\title{
Preparing Future Adaptive Experts: Why It Matters and How It Can Be Done
}

\author{
Maria Mylopoulos ${ }^{1}$ (D) \\ Accepted: 21 September 2020 / Published online: 30 September 2020 \\ (C) International Association of Medical Science Educators 2020
}

In order to meet the evolving healthcare needs of today's society, health professionals must have the capacity to handle situations involving novelty, ambiguity, and complexity. However, traditional approaches to health professions education (HPE) tend to emphasize the acquisition and assessment of isolated knowledge and skills as the gold standard. As a result, learners are often unprepared to for the realities of clinical work. This growing gap between what society needs experts to do and the training experts typically receive has resulted in the urgent need for a shift in the pedagogical focus of HPE.

"Adaptive expertise" is an emerging model of expertise in health professions education that directly addresses the challenge of preparing learners for an unknown future $[1,2]$. Models of adaptive expertise emphasize the reproduction of effective performance where applicable (efficiency), alongside the capability to "to learn new information, to use resources effectively and innovatively, and to invent new strategies for learning and problem solving in practice" (innovation) [3-5]. The latter capability is defined as "preparation for future learning" (PFL) and is the focus of pedagogical models that emphasize development of adaptive expertise [6, 7].

Critically, education for adaptive expertise requires developing both the efficiency and innovation dimensions of expert practice. This ensures that students acquire procedural fluency, i.e., reproducing effective solutions, as well as conceptual understanding, i.e., knowing the rationale and mechanisms for an action or decision. Adaptive experts are then able to draw on both procedural and conceptual knowledge in their problem solving as needed. This frees the expert from being tied to a single solution in novel or complex situations, as they are able to maintain the rationale but change the action when necessary[3-5]. Educational interventions that have been

Maria Mylopoulos

maria.mylopoulos@utoronto.ca

1 Faculty of Medicine, The Wilson Centre, University of Toronto, Toronto, Ontario, Canada shown to develop adaptive expertise include the use of productive failure [8-10], contrasting cases [11] and guided discovery [4]. Extensive evidence across the continuum of education has demonstrated that students who receive these forms of instruction perform significantly better on PFL outcome measures (i.e., assessments that require new learning) with no accompanying detriment to performance on more traditional tests of acquisition and application.

Adding to the evidence base for educational interventions in HPE that support the development of adaptive expertise is research exploring the impact of "integrated instruction" on PFL assessments. Integrated instruction is an instructional design framework for diagnostic reasoning that encompasses any pedagogical tool/approach that explicitly links clinical signs and symptoms with basic science explanations [12, 13]. For example, didactic lecture materials can be used to teach the clinical manifestations of a stroke and simultaneously explain the physiological mechanisms that cause each symptom (e.g., brainstem strokes cause unilateral weakness because the neural pathways originating in the brain control only one side of the body). Integrated instruction has been shown to support retention, diagnostic accuracy, and solving of complex cases [13-18].

Recently, it has been demonstrated that integrated instruction also supports performance on PFL assessments, when learners are required to learn new related content in order to perform successfully [19]. Integrated instruction is thought to be effective because it supports development of the conceptual understanding necessary for diagnostic reasoning by giving learners mechanistic understanding of relevant clinical concepts. This allows learners - and experts - to understand why a patient is experiencing certain clinical signs and symptoms or why a particular skill or task is performed in specific ways. Importantly, mechanistic understanding is not limited to traditional basic science explanations (e.g., anatomy, pathophysiology) and in fact can come from any knowledge domain [20]. This conceptual understanding then promotes successful transfer of learning to new problems, including those 
requiring new learning. Thus, there is an emerging evidence base for the premise that integrated instruction supports development of adaptive expertise.

In order to ensure that healthcare professionals are prepared to effectively handle and learn from the uncertainties and complexities of the evolving workplace, health professions education must develop future adaptive experts. Training must provide learners with meaningful opportunities to develop the foundation necessary to effectively apply their knowledge to routine problems, create new knowledge to handle nonroutine problems, and continuously learn as they work. Research exploring education interventions that support the development of adaptive expertise has provided meaningful evidence for guiding the design of curricula that optimally train future health professionals.

Acknowledgments I'd like to acknowledge the incredible collaboration and support I receive from my wonderful colleagues at the Wilson Centre and in particular Dr. Nicole Woods and our students in the Excel Lab (https://www.theexcellab.com/).

Data Availability Not applicable

\section{Compliance with Ethical Standards}

Conflict of Interest The author declares that there is no conflict of interest.

Code Availability Not applicable

\section{References}

1. Mylopoulos M, Woods NN. When I say ... adaptive expertise. Med Educ. 2017;51(7):685-6.

2. Mylopoulos M, Woods NN. Having our cake and eating it too: seeking the best of both worlds in expertise research. Med Educ. 2009;43(5):406-13.

3. Mylopoulos M, Kulasegaram K, Woods NN. Developing the experts we need: fostering adaptive expertise through education. J Eval Clin Pract. 2018. https://doi.org/10.1111/jep.12905.

4. Schwartz DL, Bransford JD, Sears D. Efficiency and innovation in transfer. In: Mestre J, editor. Transfer of learning from a modern multidisciplinary perspective. Greenwich, CT: Information Age Publishing; 2005. p. 1-51.
5. Hatano G, Inagaki K. Two courses of expertise. Res Clin Cent CHILD Dev Annu Rep. 1984;6:27-36.

6. Bransford JD, Schwartz DL. Chapter 3: Rethinking transfer: a simple proposal with multiple implications. Rev Res Educ. 1999;24(1): 61-100.

7. Mylopoulos M, Brydges R, Woods NN, Manzone J, Schwartz DL. Preparation for future learning: a missing competency in health professions education? Med Educ. 2016;50(1):115-23.

8. Kapur M, Rummel N. Productive failure in learning from generation and invention activities. Instr Sci. 2012;40(4):645-50.

9. Kapur M. Productive failure in learning math. Cogn Sci. 2014;38(5):1008-22.

10. Kapur M. The preparatory effects of problem solving versus problem posing on learning from instruction. Learn Instr. 2015;39:23-31.

11. Schwaltz DL, Martin T. Inventing to prepare for learning: the hidden efficiency of original student production in statistics instruction. Cogn Instr. 2004;22:129-84.

12. Woods NN, Neville AJ, Levinson AJ, Howey EHA, Oczkowski WJ, Norman GR. The value of basic science in clinical diagnosis. Acad Med. 2006;81(10 Suppl):S124-7.

13. Baghdady MT, Carnahan H, Lam EWN, Woods NN. Integration of basic sciences and clinical sciences in oral radiology education for dental students. J Dent Educ. 2013;77(6):757-63.

14. Kulasegaram K, Manzone JC, Ku C, Skye A, Wadey V, Woods NN. Cause and effect: testing a mechanism and method for the cognitive integration of basic science. Acad Med. 2015;90(11): S63-9.

15. Lisk K, Agur AMR, Woods NN. Exploring cognitive integration of basic science and its effect on diagnostic reasoning in novices. Perspect Med Educ. 2016;5(3):147-53.

16. Cheung JJH, Kulasegaram KM, Woods NN, Moulton C-A, Ringsted CV, Brydges R. Knowing How and Knowing Why: testing the effect of instruction designed for cognitive integration on procedural skills transfer. Adv Health Scie Educ. 2018;23(1):6174.

17. Kulasegaram KM, Martimianakis MA, Mylopoulos M, Whitehead CR, Woods NN. Cognition before curriculum: rethinking the integration of basic science and clinical learning. Acad Med. 2013;88(10):1578-85.

18. Woods NN, Brooks LR, Norman GR. The role of biomedical knowledge in diagnosis of difficult clinical cases. Adv Health Sci Educ. 2007;12(4):417.

19. Mylopoulos M, Woods N. Preparing medical students for future learning using basic science instruction. Med Educ. 2014;48(7): 667-73.

20. Chaudhary ZK, et al. Reconsidering basic: integrating social and behavioral sciences to support learning. Acad Med. 2019;94(11S) Association of American Medical Colleges Learn Serve Lead:S73-8.

Publisher's Note Springer Nature remains neutral with regard to jurisdictional claims in published maps and institutional affiliations. 